\title{
Nos rincões de Goiás... a construção de um território citadino
}

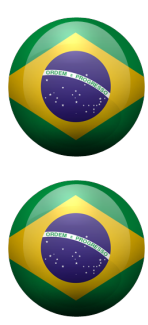

\section{Gercinair Silvério Gandara}

Docente da Universidade Estadual de Goiás. Pós-Doutora em História [UFG]. Doutora em História Social [UnB]. Coordenadora do Laboratório de História e Estudos Multidisciplinares em Ambientes. Líder do Grupo de Pesquisa Rios e Cidades na História do Brasil. Goiânia [GO] Brasil. <gercinair@msn.com> Jennydavison Ribeiro dos Santos Batista

Mestre em História pela Universidade Federal de Uberlândia, Especialista em História Afro Brasileira, Graduada em História pela Universidade Estadual de Goiás. Uberlândia [MG] Brasil.

<jennydavisonrsb@hotmail.com>

\section{Resumo}

Neste texto discutimos elementos relevantes da formação histórica do surgimento da cidade de Orizona (estado de Goiás) que em sua constituição foi fortemente influenciada pela Igreja Católica e pelos grandes latifúndios. Para garantir a compreensão da sua memória social buscamos ler o que fosse significativo dentro do vasto repertório de elementos que compõe a história do seu surgimento. Evidenciaremos o que representou a fé católica para a construção do território e outros elementos relevantes da formação histórica e das relações socioculturais que evidencie a recusa aos dormentes em sua estrutura citadina.

\section{Palavras-chave}

Cidade. Território. Raízes urbanas. História. Giros.

\section{In the corners of Goias... building a city territory}

\begin{abstract}
In this paper we discuss relevant elements of the historical formation of the emergence of Orizona city (state of Goias) in which constitution was strongly influenced by the Catholic Church and mega farms (known as "latifundios"). In order to ensure understanding of their social memory we seek to show what was significant in the vast repertoire of elements that make up the history of its emergence.We will show what the Catholic faith meant to the construction of the territory and also show other relevant elements of the historical development and socio-cultural relations that highlights the refusal to trail in your city structure.
\end{abstract}

\section{Keywords}

City. Territory. Urban roots. History. Spins. 


\section{Introdução}

0 terreno em que surgiu a cidade de Orizona situa-se na região do sudeste goiano. Está localizada na região da Estrada de Ferro Goiás, embora não faça parte do itinerário traçado pelos trilhos. Ocorre que esta ferrovia alcançou somente o povoado de Ubatã, depois cognominado de Egerineu Teixeira, localidade que fica a doze quilômetros do local em que se erigiu a cidade de Orizona. 0 então Arraial Capela de Nossa Senhora da Piedade de Campo Formoso foi construída sobre uma escarpadura do ribeirão Santa Bárbara, numa paisagem que, em termos gerais, correspondia ao cerrado goiano era um centro regional sensivelmente relacionado com seu entorno, mas também uma organização urbana que antecipava aos moldes da "modernidade" advinda com os trilhos. Foi tecido aos moldes dos grandes latifúndios em que se erigia uma capela e em torno dessa surgia um núcleo amplamente dominado pela tradição e costumes da igreja Católica. A maneira exata como foi urdido no tecido histórico e ideológico de seu tempo talvez revele melhor na história oitocentista goiana. Se se a cidade é a imagem do corpo social devemos reconhecer o diálogo entre a cidade viva do/no passado, o ribeirão e a lembrança esmagadora da possibilidade da passagem da "estrada férrea" lhe cortando as entranhas e determinando o seu caráter e o seu fascínio.

Orizona originou-se da Capela dos Correios dedicada à nossa Senhora da Piedade. Esta capela foi edificada à margem direita do ribeirão Santa Bárbara afluente do rio Corumbá. Em 1890 foi erigido a distrito com esta denominação. Em 12.07.1906 pela Lei no277 foi elevada a categoria de Vila com a denominação Campo Formoso e em 1909 pela Lei no 347 elevou-se a categoria de cidade. 0 município denominou-se Orizona pelo Decreto-Lei de 305 de 31.12.1943. Segundo os orizonenses esta denominação significa "terra do arroz"1. A cidade situa-se na parte central do município entre os municípios de Vianópolis, Silvânia e Luziânia ao norte separados pelo rio Piracanjuba, Pires do Rio e Urutaí ao sul, Ipameri a leste, Pires do Rio e Vianópolis a oeste. 0 rio Corumbá separa o município de Orizona dos de Ipameri e Urutaí. Este município é recortado por ribeirões e córregos no sentido norte-sul indo suas águas para o rio Paranaíba. Além do distritosede possuem outras aglomerações urbanas, os conhecidos "povoados". Cachoeira as margens do ribeirão do mesmo nome, Corumbajuba, Montes Claros e Egerineu Teixeira servido pela Estrada de Ferro Goyás.

\section{Cidades... território dos espaços vividos}

A história das cidades tem importante missão a cumprir do ponto de vista da memória social histórica. As imagens das cidades, as representações urbanas constituem um dos componentes da prática social global, que inclui o universo de valores, as aspirações e as legitimações. 0 historiador francês Roger Chartier (1990, p.13-28) propõe um conceito de cultura enquanto prática sugerindo para o seu estudo as categorias de representação e apropriação. Este historiador pensa a representação quer como algo que permite "ver uma coisa ausente", quer como "exibição de uma presença". Para ele o social só faz sentido nas práticas culturais. Silva (2000, p.129-130), nos alerta que entender a cidade como forma social significa concebê-la como resultante material e sempre atual do campo de forças sociais. Destacamos que concebemos as cidades como historicamente capazes de explicar seu território e mobilizar as atitudes dos indivíduos e dar sentido às suas ações.

Consideramos o espaço urbano enquanto uma estrutura cujos elementos principais numa grande medida determinam o aspecto da cidade. Tal abordagem nos permitiu pensar a cidade Orizona em seu princípio com seus valores, sua cultura, enfim, numa análise social. Buscamos entendê-la tendo como pano de fundo sua sociedade em processo de constituição, portanto, em movimento. Significou pensá-la a partir das relações sociais em sua natureza social e histórica. A sua realidade, as formas de ocupação, as origens dos seus habitantes e suas ligações com as mudanças e expansão do espaço constituem o sentido da história da cidade. Essa perspectiva permitiu que rompêssemos com uma unidade que nunca existiu e que reclama por uma história própria. Esta cidade numa fração de espaço é projeção das heranças históricas, de esforços econômicos, administrativos, arquitetônicos e de hábitos e aspirações quotidianas. A imagem do espaço da cidade não revela extraordinariamente uma luta, mas um trânsito de valores, usos e

\footnotetext{
${ }^{1} 0$ termo "Oriza" significa "Arroz".
} 
hábitos que unifica, senão econômica, certamente cultural. Para o historiador ela é também um objeto político com suas instituições políticas e administrativas. Antes que um refinamento ou sofisticação ela é uma condição de produção e reprodução da sociedade. A cidade num sentido forte é o espaço de um relacionamento partilhado e reconduzido, a história de famílias tradicionais repetida e repisada. Ela não é um espaço neutro, é um território que comporta forças de sobrevivência. Para Rogério Haesbaert (1995), o território tem uma dupla face. É um espaço dominado ou apropriado com um sentido político, mas também apropriado simbolicamente, onde as relações sociais produzem ou fortalecem uma identidade utilizando-se do espaço como referência. Neste sentido, a dupla dimensão do território, cultural e político-disciplinar pode estar conjugada, reforçada ou ainda contradita, devendo ser analisada de acordo com as formas e a intensidade com que se apresenta a relação entre a dimensão material (político-econômico) e a dimensão imaterial (simbólico-cultural).

A transformação da categoria espaço em território é um fenômeno de representação através do qual os grupos humanos constroem sua relação com a materialidade, num ponto em que a natureza e a cultura se fundem. Muitos priorizam a dimensão simbólico-cultural na construção do território, considerando-o como uma identificação que determinados grupos desenvolvem com seus "espaços vividos". Felix Guatari entende que, "... o território pode ser relativo tanto a um espaço vivido, quanto a um sistema percebido no seio do qual um sujeito se sente 'em casa'". Destarte o território é sinônimo de apropriação, de subjetivação fechada sobre si mesma. É o conjunto dos projetos e das representações nos quais vai "desembocar, pragmaticamente, toda uma série de comportamentos, de investimentos, nos tempos e nos espaços sociais, culturais, estéticos, cognitivos". (Guatari, 1985, p.110). Neste sentido o território é uma categoria em que são apreendidos cenários contíguos e alternos adjacentes e separados, dependendo às vezes do tipo de interações estabelecidas com as relações, os repertórios culturais e os "mundos" de vida. É, portanto, um dos aspectos paradoxais da identidade cultural. Creio que a territorialidade se dá por meio de um processo de criação de códigos e símbolos que caracterizam e particularizam um lugar para um indivíduo ou grupo. Este lugar está intimamente ligado às relações travadas entre as pessoas no decorrer do tempo e o lugar. Territorialidades assim são essencialmente múltiplas, pois os agentes individuais têm percepções divergentes e admitem a co-presença de alteridades culturais. De uma forma ou de outra, entendemos que uma das formas concretas de apropriação temporal-espacial mediada pelo poder é o território. Acreditamos, também, que a territorialidade está presente em qualquer representação social cuja intenção seja definir as fronteiras de controle e apropriação de determinada realidade social. Neste sentido compartilhamos de uma territorialidade relativa além da fachada do comportamento social humano ou da moldura perene das estruturas espaciais. Trata-se de uma estrutura social dinâmica vivenciada no cotidiano urbano sob forma de representações sociais por meio da dita "modernidade". Numa palavra, a noção de território, sem dúvida, é formada através do dado imediato da materialidade, mas esse é apenas um componente, já que todas as demais representações são abstratas. Vale lembrar que o território esteve muito vinculado ao controle do poder estatal e à constituição do espaço Estado-nação. Esta visão de território é uma criação cultural que estabelece certa rigidez de suas fronteiras e uma fixidez temporal do controle do espaço físico. Muitos autores têm contestado esta simplificação, dando ênfase ao caráter político não-estatal na construção do território.

As cidades refletem certa organização da sociedade. Torna-se importante, pois, explicar a origem de cada cidade e também seu destino, suas peculiaridades e características que são motivo de muitos estudos e pesquisas que levam ao esclarecimento de suas especificidades e à multiplicação das leituras da cidade, como sugeriu Barthes. De fato, o espaço cidade é uma construção da sociedade consequentemente sua própria realização. Como diz Fremont, (1980, p.238), "a sociedade e o espaço estruturam-se a partir das cidades". E reforça Isnard (1982, p.70-75) "a organização do espaço cria entre o homem e o meio laços místicos que realizam uma íntima adaptação do social e do espacial". Sabe-se que todos os níveis de coletividades são interessados pelas relações e pelas interações. A cidade, tal como é encontrada na História, é o ponto de máxima concentração do vigor e da cultura de uma comunidade, diz Munford (1961, p.13). Seria difícil imaginar uma afirmação mais concisa dos preceitos econômicos e técnicos básicos para a fundação e organização de uma cidade. A própria lucidez deste esboço reflete, em seu tom e conteúdo, a natureza do surgimento da cidade Orizona. 


\section{Surgimento do Arraial nas Escarpaduras do Ribeirão Santa Bárbara}

Pensamos que o primeiro passo ao se interrogar um espaço caracterizado como cidade deve ser, antes de tudo, entendê-lo como sendo constituído pelas relações sociais e políticas que se tecem numa dialética que perpassa os limites, visíveis ou invisíveis, do seu surgimento. Sabemos que uma cidade não se deixa objetivar, pois seus aspectos arquitetônicos advêm de uma aglutinação de saberes e experiências construídas com o passar dos anos que refletem a identidade daqueles que a construíram. Segundo Bourdieu (1998, p.144), "o espaço social e as diferenças que nele se desenham espontaneamente tende a funcionar simbolicamente como espaço de estilos de vida". Assim, o estudo sobre estes espaços cidades nos levam a entendê-lo como único. Suas particularidades retratam dimensões, originais e dinâmicas, construídas no cotidiano que nos levam a pensar formas diferenciadas de reflexões.

Foi por volta de 1850, em meio a dimensão histórica da cidade colonial de Santa Cruz de Goiás que em sua região surgia um pequeno Arraial denominado Capela de Nossa Senhora dos Correias. Um arraial pensado e desenhado, inicialmente, com o intuito de atender as necessidades da fé católica aos moradores rurais da localidade próxima e aos migrantes sertanejos que por ali passavam. Para tanto os moradores da região construiu uma Capela destinada à Nossa Senhora da Piedade. Esta foi a primeira obra no território que, mais tarde, se tornaria o Arraial de Capela Nossa Senhora da Piedade dos Correias. Como se vê Orizona adveio da vontade de fazendeiros da região sudeste goiana para atender a fé católica surge, portanto, sob domínio da Igreja Católica. Vale ressaltar que em seu nascedouro havia ali agricultura de subsistência. Como diz Raymond Williams (2011, p.11) campo e cidade são palavras poderosas... se aquilatarmos o quanto elas representam na vivência das comunidades humana. Em Orizona o campo foi associado de tal modo à cidade como centro de suas realizações e forma natural de vida cristalizando e generalizando atitudes emocionais poderosas de "paz e virtudes simples". A vida e as relações entre a cidade de Orizona e o campo/fazendas é uma história ativa e contínua. "A vida do campo e da cidade é móvel e presente, move-se ao longo do tempo, através de uma história de uma família e um povo; move-se em sentimentos e ideais, através de uma rede de relacionamentos e decisões" (Williams, 2011, p.21).

As primeiras notícias que encontramos sobre o território adveio dos viajantes estrangeiros que fizeram as primeiras representações históricas da região. No caso dessa localidade viria a ser Campo Formoso iniciou no século XVII. A descrição feita pelos viajantes no local que conforme o Livro do Tombo traz notícias dos primeiros caminhos que seriam traçados para o futuro núcleo de Campo Formoso. Nos seguintes termos diz os escritos:

Dentro dessa grande região ocultava-se para o futuro a paróquia de N. Senhora da Piedade de Campo Formoso, hoje Orizona, antiga Capela dos Correias. Com os pontos de referência já conhecidos desde o seculo desoito, como sejam: Passagem do Corumbá, em 1726, Santa Cruz em 1729, Garimpo dos paulistas desde de 1746, Minas do Senhor do Bonfim já em 1774, a zona em apreço só começou a ser povoada em princípios do século desenove. È bem verdade que o Rio Corumbá é para o conhecimento de Goiás um dos maiores fatores, porem se apresenta como caminho para as Minas do Norte de Goiás. (Livro do Tombo, 1912, p.1).

Além dessa descrição nas suas anotações Pe. Tridade dá conta da localidade (1945) que com o reconhecimento da região nos trabalhos de Saint-Hilaire, Luiz D'Alincourt, e Cunha Matos dizendo este último, "entre o porto Corumbá e a Capela de Bom fim, já em 1826 existiam esses dois grandes pontos de referência, para o lado sul o engenho do Bahú, e para o lado norte o rancho do Basílio" (Livro do Tombo, p. 75)

Oficialmente, 1850 foi o ano da fundação do Arraial, mas no Livro do Tombo Pe. Ramiro Meireles afirma que o vigário Antônio Ferreira de Lima era responsável pelos "giros" nesta região. Portanto, anteriormente, ao ano de 1850 a presença dos representantes religiosos era muito importante para o apoio aos fiéis nas dificuldades e em algumas esparsas anotações já se descrevia a Fazenda Santa Bárbara. Local de onde a faixa de terras fora desmembrada para a construção do povoado por meio de uma doação feita ao patrimônio Católico. Diz Fábio Guimiero que [...] 
[...] a presença de instituições religiosas entre a sociedade colonial brasileira era de certa forma um consolo aos fiéis, que muitas vezes, devido à falta de padres diocesanos, ficavam devendo em suas obrigações religiosas, estes casos eram geralmente resolvidos pelos religiosos que auxiliavam atendendo confissões e pregando nos mais longínquos lugarejos da colônia tanto no tempo quaresmal como em outras épocas do ano, quando organizavam incursões ao interior para pregar missões e catequizar os moradores (Guimieiro, 2013, p. 68).

De um modo ou de outro o Arraial de Nossa Senhora da Piedade dos Correias pertencia ao julgado de Santa Cruz de Goiás. As primeiras notícias do seu surgimento, conforme Livro do Tombo (1945, p.2) se deu em 1830 quando "começaram a aparecer os logares que no futuro formarão o território da Nossa Senhora da Piedade". Quanto a fundação da cidade, que em seus relatos Pe. Ramiro Meireles buscou dissipar dúvidas sobre a fundação do Arraial. o Pe. Trindade no livro do Tombo de 1945, afirma que "baseado em alguns apontamentos esparsos deixados pelo saudoso Pe. Ramiro de Campos Meireles podemos alcançar com segurança os principais nomes que a posteridade possa cultuar" (Livro do Tombo, 1945, p.4). Nos escritos do Livro do Tombo fala-se sobre um dos possíveis doadores das terras para a construção da Capela de Nossa Senhora da Piedade, [...]

[...] nessa mesma data e logar aparecem os nomes do tronco que mais tarde vem cognominar a Capela dos Correias, assim entre diversos, João Correia, o mérito sobre todos, de ser quem doara a Nossa Senhora da Piedade a faixa de terras (?) que constitui o patrimônio da igreja Matriz. [...] Auscultando a opinião dos mais velhos da paróquia, todos são unânimes na afirmação de ser esse João Correia, a figura central da gênese da Capela, hoje Orizona (Livro do Tombo, 1945, p.3).

Outras doações feitas pelos seguidores da fé cristã Católica parecem ter sido de igual importância, pois a todo tempo aparecem mencionadas nos sermões e cartas pastorais lembrando aos fiéis a importância impar das contribuições por eles ofertadas. No período republicano, a carta pastoral feita por D. Prudêncio Gomes da Silva, então Bispo de Goiás a 19 de maio de 1913 endereçada a recém-inaugurada Paróquia Campo Formoso se legitima e justifica a necessidade dos óbolos.

De D. Prudêncio Gomes da Silva, Bispo de Sant'anna de Goyaz, annunciando a sua próxima viagem a Roma e publicando a Encyclica de S. Santidade o Papa Pio X. D. Prudêncio Gomes da Silva por mercê de Deus e da S. Sé apostólica Bispo de Sant'anna de Goyaz. [...] é a visita que lhe cumpre fazer ad limina apostolum. Três atos comprehende esses meus: a visita material a basílica de são Pedro e são Paulo, prestação de obediência e reverência ao summo pontífice e apresentação de um relatório sobre o estado material da diocese. [...] a igreja em particular a fim de não usurpar coisa alguma das que sejam aptas a aumentar a glória de Deus, propagar a religião christan e procurar a salvação das almas. [...] para fugir a esse grave dever costumão alguns objetar que o Papa não precisa de nossas esmolas, que habita um impetuoso palácio etc. Nada mais injusto, si pensarmos que não podemos calcular o quanto despende S. Santidade annualmente com os gastos do vaticano e suas dependências, com as congregações e secretarias Romanas com os Collégios de Roma, com as missões estrangeiras. [...] fora isso lembrem nos que por ocasião das grandes catástrofes, o S. Padre é um dos primeiros a enviar, além da consolação propria de um pai afflicto, avultadas esmolas para matar a fome, estancar sede, enxugar lágrimas e amparar órfãos. [...] esse edifício não é do Papa, é dos Papas, pertence a christandade (Carta Pastoral: 1912).

Confirma-se, portanto, que as doações feitas pelos fiéis traziam ainda muitas vantagens ao clero, pois "nas mãos da Igreja ficava também a obra de transmitir à população os rudimentos de cultura necessários à sua cristianização" (Costa, 2010, p. 241). A instituição católica em Campo Formoso era fortemente representada, principalmente, pela figura dos padres, pois, estes estavam em contato mais próximo com a comunidade sempre desempenhando importante papel na formação cultural e social da sociedade local. 
O prédio que abrigou a futura freguesia de Nossa Senhora da Piedade foi construído a partir de 1853 tornando-se pública em 1866 quando foi entregue à devoção de Nossa Senhora da Piedade. Com a morte do capitão Fulgêncio Caetano de Souza em 1857 a capela foi terminada por uma comissão de antigos moradores, liderada pelo capitão José Pereira Cardoso.

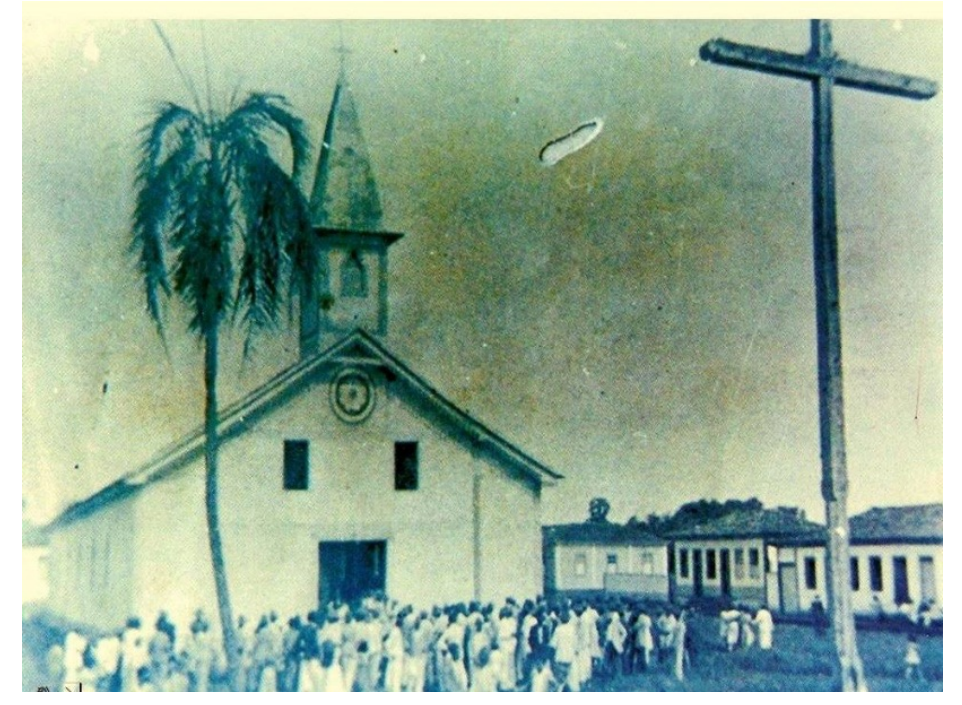

Figura 1. Capela entregue à devoção de Nossa Senhora da Piedade. Fonte: Helder Gonçalves. Jornal Terra Goiana Rua Francisco Dias Pimpão 46 Centro Orizona [GO].

Nesta região os chamados "giros"2 foram motivação para a construção da Capela Nossa Senhora da Piedade. Estes conhecidos "giros" católicos eram feitos para atender aos fiéis no cumprimento das suas obrigações religiosas em diversas regiões do interior, sendo que o Arraial de Nossa Senhora da Piedade dos Correias era visitado pelo menos três vezes ao ano. As práticas eram feitas para que os fiéis não ficassem sem assistência religiosa. Os "giros" dos padres se faziam em lugares predeterminado para que várias famílias/pessoas participassem das obrigações, tais como, batismos, casamentos, confissões e a extrema unção. Estes lugares foram descritos no Livro do tombo de 1836 onde aparece os nomes do sítio do Bahú, "onde se batizam muitos inocentes, Cocal, Santa Barbara, Cuiabanos, Taquaral, Cachoeira, Posses, Piracanjuba, Engenho Velho, Boa Vista, Campo Alegre, como se depreende no Livro de registro do Pe. Calado e o Pe. Joaquim Ferreira" (Livro do Tombo, 1912, p. 2). Mesmo depois da construção da capela e da emancipação da cidade de Orizona os padres católicos continuavam fazendo os "giros" no intuito de zelar do rebanho de fiéis católicos. 0 próprio Pe. Tridade na década de 1940 ainda visitava os povoados distantes da cidade de Campo Formoso realizando missas, batizando, comungando e (re)formando os votos à Igreja. Ele, também, reivindicava doações de patrimônios para construir igrejas nos povoados, a exemplo podemos mencionar o caso da Capela de Santa Luzia no Povoado de Egerineu Teixeira:

A capela de Santa Luzia de Ubatan, hoje Egerineu Teixeira, encontramó-la no mais completo desprezo [...] hoje está reconstruída com todo o necessário para amplo exercício do culto divino ao lado de um povo bom; a referida capela que até o presente momento não possui patrimônio a não ser a praça onde está edificada (Livro do Tombo, 1945. Pe. José Trindade, p. 20).

Como em muitas outras cidades brasileiras a Igreja Católica foi fundamental para o surgimento do Arraial de Nossa Senhora da Piedade dos Correias. A Igreja construída por meio de uma doação foi o elemento definidor do seu surgimento. São várias fontes e documentos que comprovam essa influência religiosa que título de exemplo podemos mencionar os Livros do Tombo da Paróquia de Campo Formoso. Neles encontra-se descrito o histórico da cidade com as primeiras notícias do seu afloramento enriquecido por comentários pessoais e impressões do Pe. Ramiro Meireles que suas anotações justificara ser seus relatos "uma inquietação advinda do temor de não se trazer à luz da história acontecimentos que poderiam se perder para sempre no tempo".

\footnotetext{
${ }^{2}$ Giros -peregrinação dos padres católicos que visitavam, pelo menos três vezes ao ano, diversas regiões do interior levando assistência religiosa, tais como, batismos, casamentos, confissões e a extrema unção.
} 
Mas a Igreja influenciou, também os governos locais. Conforme Sérgio Micelli (1988, p.21), "as figuras-chave na condução da política eclesiástica destinada ao público interno passaram a ser aqueles bispos 'empresários' que se mostraram bem-sucedidos na montagem de alianças como detentores locais do poder oligárquico".

Mas há outras versões sobre a fundação da cidade de Orizona. Dizem que o povoado chamado Capela dos Correia fundada no ano de 1850 foi assim batizado por que um homem chamado Fulgêncio Correia Peres, proprietário das terras pela primeira vez, teria erguido uma Capela a Nossa Senhora da Piedade para que se rezassem missas dominicais. Dessa forma aos seus arredores foram construídas casas de sapê, e famílias foram fixando residência. Logo depois os Correia doaram estas terras para igreja Católica. O povoado progrediu sendo como Vila denominado Campo Formoso. Orizona, segundo a comunidade local, fora um nome escolhido pelo médico Dr. Rafael Leme Franco, apesar, dizem eles, "de muitos não concordarem". Noutra versão, conta-se que a cidade de Orizona começou a se constituir em 1830 quando caçadores / agricultores vieram de Minas Gerais pelos caminhos de Santa Cruz com destino a Bonfim hoje cidade de Silvânia. Ali se deram conta de uma grande mata situada entre o córrego do Retiro, hoje chamado de Cortado, e o ribeirão Santa Bárbara. Contam os citadinos que um desbravador chamado José Pereira Cardoso, nascido em Patos de Minas, veio mata adentro e tomou posse de mais ou menos 12 mil alqueires de terras goianas. Depois passou a morar no local denominado fazenda Salto, e aí se deu o início do povoado do mesmo nome em razão do ribeirão.

Em 1906 o Arraial de Nossa Senhora da Piedade dos Correias foi elevado à categoria de Vila Campo Formoso, pelo decreto 277/1906, emancipando-se de Santa Cruz de Goiás. Foi instalado o Conselho de Intendência, pelo coronel José Pereira da Costa Sobrinho, figura influente na região. Com a instalação do Conselho de Intendência elevou-se o Arraial Capela dos Correias para categoria de Vila estipulando os limites do distrito e do município de Campo Formoso. Liderado de perto, a princípio, pela figura do coronel José da Costa Pereira Sobrinho o Conselho foi a materialização dos sonhos de uma classe social dominante local que, via no arraial um cenário promissor para os desejos de prosperidade e modernização da região. Na prática a instalação do Conselho pouco modificou a vida no local, pois os municípios representados pelos Conselhos de Intendência se limitavam, em diversos aspectos, como uma extensão do poder estadual assim, "pouco mais restava aos intendentes do que a representação dos interesses do Executivo Estadual" (Santos, 1982, p.6). Mas, ao se atingir esta categoria, podia-se baixar códigos de posturas e decretar Leis. Destarte, a partir de 1909, a Vila de Campo Formoso fora elevada à categoria de cidade.

\section{Organização Territorial de Campo Formoso}

Os Códigos de Posturas foi uma das primeiras providências para organização do território de Campo Formoso elevado à categoria de Vila. Estes códigos englobavam uma série de medidas reguladoras da/na organização espacial, social e de salubridade. O Sr. Heitor Ferreira Carvalho (2004, p.32) conceitua o Código de Posturas como "um conjunto de instrumentos normativos que estabeleciam parâmetros gerais para o convívio em sociedade". Já para Le Goff $(1998$, p. 7) o código de posturas era a "idealização de um instrumento que pudesse contribuir para uma cidade vir a ser mais 'moderna e civilizada', porque a cidade, bela e rica, é também fonte de idealização". Ademir Gebara (1986, p. 101) diz que os códigos de Posturas "referem-se a um grande número de questões pertinentes à administração pública municipal, sendo uma excelente fonte para o estudo da história local por revelarem inúmeros aspectos da vida diária como os costumes e problemas enfrentados pela comunidade".

Em Campo Formoso essas normatizações comprovam o empenho para que ali se tecesse convívio social. A vila passou ao epicentro das disputas das elites local que assumiria a liderança política e administrativa da localidade. Dessa elite partiria as decisões que regularia a vida dos moradores em seu cotidiano urbano. Heitor Ferreira Carvalho (2004, p. 31). Nos explica que "o espaço urbano, anteriormente usado por todos os munícipes em encontros coletivos, festas, mercados, convívio social etc., começa a ser governado por um novo interesse, em meados do século XIX e início do XX, que é o interesse público controlado pelas elites dominantes". 
Com normatizações dadas pelo Código de Postura a cidade passou a ser pensada como um local que se pautaria pelo melhor convívio social com melhores condições de moradia e saúde. "Nesse sentido, surge à preocupação com a higiene pública, com, [...] o clima e suas doenças etc." (Silva, 1998, p.134). As palavras de ordem advindas pelo Código de Posturas eram ruas alinhadas e niveladas, casas arejadas, salubridade, embelezamento, segurança, dentre outros. Ficava a cargo do intendente municipal colocar as coisas em ordem. Para tanto dependia das figuras marcantes dos fiscais do Conselho. A eles dentro dos limites da Vila cabia autuar, inscrever, punir, aplicar multas, indiciar, além de lavar os canteiros dos muros sujos pelos lodos, fiscalizar anéis d'água, e até mesmo matar formigas "as cabeçudas" que eram como pragas nessas paragens. Também dar fim aos cães que não tivessem donos. Cabia, também, aos fiscais do Conselho aplicar multas como também poderia sofrer multa caso descumprisse qualquer de suas atividades ou algo lhe passasse despercebido. 0 art. 168 do Código de Posturas de Campo Formoso de 1907 postulou que "o fiscal é funcionário municipal especialmente encarregado de zelar pela boa execução destas posturas impondo multas aos seus infratores. Já o art. 182 rezou [...]

[...] "todo indivíduo que insultar o fiscal no exercício de suas funções ou se opuser ao desempenho dos deveres de seu emprego, será preso e recolhido a cadeia à ordem do Intendente, a fim de sofrer a multa de $30 \$ 000$, trinta mil réis e oito dias de prisão".

Estes artigos procuraram inibir atitudes hostis em relação aos fiscais da Intendência, uma vez que toda e qualquer infração seriam penalizadas sob forma de multas, prisões simples ou com trabalho e a obrigação de fazer ou desfazer ação dependendo de cada caso em particular. Sempre que se infringia o Código sem a licença do conselho ou fora das posturas da cidade se atribuía obrigação ao responsável de fazer ou desfazer no prazo médio de cinco dias. Observamos em nossa análise documental que existia uma pesada carga de impostos e de multas, mas os moradores quase nunca cumpriam uma vez que quase nunca podiam pagar as cobranças da Intendência. Assim resultava em multas que eram somadas aos impostos. Encontramos cartas dirigidas à intendência com reclamações sobre a cobrança excessiva de impostos. As regras impostas pelos Códigos de Posturas resultavam de práticas abusivas executadas pelos munícipes de forma aleatória, implicando quase sempre em desordens. As multas eram cobradas em Real, unidade monetária do período "cujo o plural era expresso pelo termo réis" (Nascimento, 1999, p.20). A força pública indicava todo comportamento por meio do Código de Posturas. Também delimitava o espaço no caso de aberturas de ruas, que ficavam proibidas a qualquer cidadão abrir sem a licença prévia dos conselhos. Todos poderiam ser penalizados com tais regimentos até mesmo os tropeiros, viajantes, mascates, carreiros. Estes pagavam ao fiscal ao ato da infração por não residirem na vila, pois, somente sujeitos domiciliados a mais de um ano é que seriam considerados do local. As multas aplicadas nos reincidentes teriam seu valor duplicado. As penalizações eram variadas, porém qualquer sujeito poderia estar nelas incursas. Na realidade, os códigos de posturas foram mecanismos de controle social, em que se buscava destruir hábitos tradicionais que pudessem ser considerados como "não civilizados" substituindo por outros considerados polidos.

O Código de Posturas de 1907 regulou as moradias da Vila Campo Formoso. Nele consta que as casas não poderiam colocar suas portas, janelas, rótulas, ou empanadas de qualquer espécie se abrindo para o lado de fora, a não ser no caso das janelas, desde que ficassem a dois metros e vinte centímetro acima do nível do passeio. Era uma inovação, pois, janela com abertura para fora era excepcional, pois, o usual eram as alcovas ${ }^{3}$ largamente reproduzidas dos tempos coloniais. Mas a Intendência só permitiria o uso dessas janelas com a condição de serem pintadas à tinta óleo ou caixilhos com vidraças. Os muros ou grades fechariam todos os terrenos com altura mínima de dois metros de altura. Ficou proibido cercas de aroeiras, ou qualquer madeira, varas, espinhos, valas a partir de 1ำ de janeiro de 1907. Proibidos, também, estavam as construções de casas de meia água, sob qualquer pretexto. Degraus e escadas somente poderiam ser feitos para dentro

\footnotetext{
${ }^{3}$ As alcovas são de origem árabe, al-kobba significa esconderijo (Mérito, 1957), local onde se busca segurança. Também é o quarto da mulher e por extensão, o quarto de dormir, onde o território individual ou de um grupo familiar é marcado. No século XIX, alcova era o quarto dos prazeres, um espaço muitas vezes sem ventilação, nem iluminação: o ambiente mais privado da casa. Atualmente, pode-se afirmar que a alcova é um espaço relacionado à territorialidade e ao espaço íntimo e pessoal, onde o acesso não é permitido a qualquer um; ela é importante porque a privacidade é uma necessidade do ser humano desde a concepção (Dicionário Larousse).
} 
das soleiras das portas jamais para as calçadas. Colocar janelas, clarabóias, frestas de qualquer tipo ficavam terminantemente proibidos se fossem para terrenos alheios ou públicos.

Nas construções das casas tinham-se preocupações para que obedecesse a simetria tendo o cuidado de se ter três metros e vintes centímetros do baldrame à parte superior do telhado. 0 título que trata do alinhamento da Vila inclina para que as ruas, praças, casas, sobrados, chalets, todos fossem edificados de modo simétrico trazendo beleza a cidade. Em desobediência a essa norma as multas aplicadas eram de cinco mil réis até trinta mil réis. Todos os alinhamentos eram concedidos pelo Intendente e transcritos para um livro próprio onde se registrava para se ter efeito. Ao ofício de alinhador cabia as medições e os alinhamentos das casas e prédios. Para tanto se estipulava o valor de cinquenta réis por cada metro alinhado. Os sobrados mediriam quatro metros de altura no pavimento do térreo e o andar superior deveria conter três metros e cinquenta da linha superior ao perímetro da linha o telhado. As janelas mediam um metro e trinta centímetros de altura por noventa centímetros de largura devendo ainda ter um metro do baldrame a face superior do peitoril. As portas mediriam dois metros e quarenta centímetros. Determinava o Código de Posturas que as casas fossem caiadas e rebocadas de três em três anos e as tintas a óleo repintadas no mesmo prazo. As regras previam casas arejadas para que obtivessem maior conforto e saúde aos moradores. 0 sol era um mecanismo de salubridade por isso a exigência de janelas altas e largas. Não havia restrições em seu número. Como se vê o fator da salubridade foi elemento que requereu atenção das autoridades como fator decisivo na melhoria de vida dos moradores. Na arquitetura da cidade nota-se alguns exemplares de inspiração neocolonial com telhados aparentes. Mais tarde algumas moradias foram construídas influenciadas pelo Art Déco optando pelas platibandas.

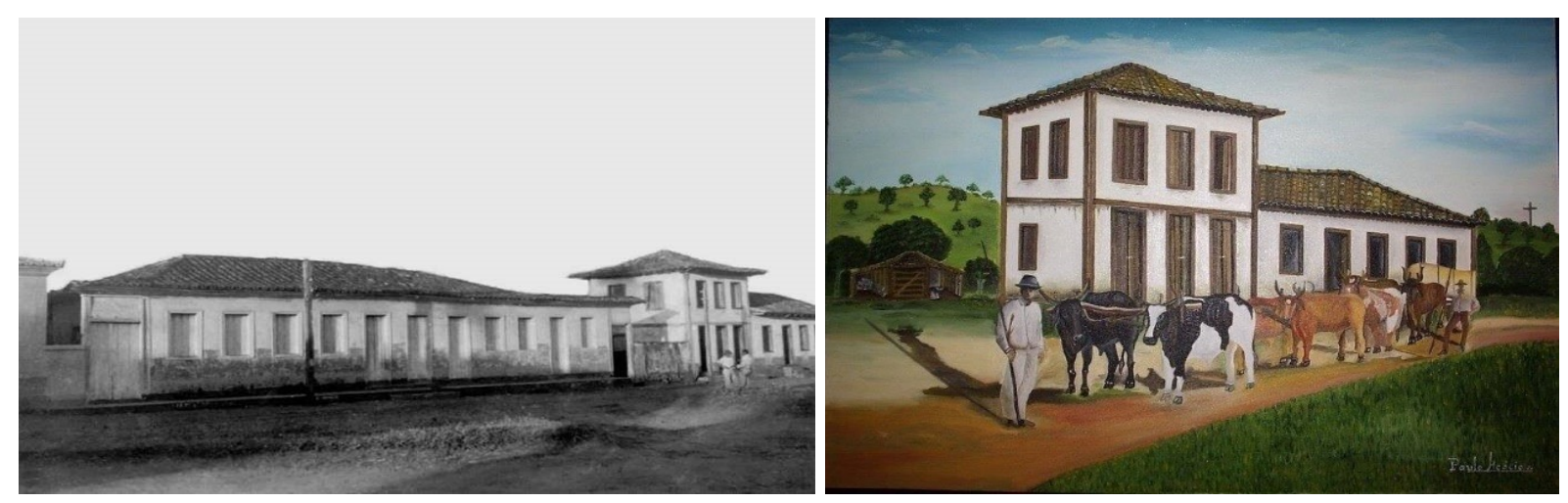

Figuras 2 e 3. Moradias em Campo Formoso influenciadas pelo Art Déco: Fotografia à esquerda (Figura 2) e Pintura à direita (Figura 3). Fonte: Helder Gonçalves. Jornal Terra Goiana Rua Francisco Dias Pimpão 46 Centro Orizona [GO].

Havia preocupações com a harmonia nas relações entre construções e logradouros públicos. Para tanto determinou-se que nenhuma rua ou travessa poderia ser aberta na cidade que não fosse pela Intendência. Nenhuma porta e/ou portões poderiam abrir para fora, entulho, caixões eram proibidos nas calçadas, pois, poderiam obstruir os passeios impedindo a livre circulação. Os responsáveis eram obrigados a retirá-los sob pena de multa de $20 \$ 000$ vinte mil réis por descumprimento. As ruas e travessas deveriam conter treze metros de largura. As praças vinte e cindo metros quadrado. Este modelo de praças foi herdado de Portugal em que as praças se faziam quadradas ou retangulares prezando pelo desenho "matemático e geométrico". Parafraseando Deusa Maria Boaventura (2007) era das praças centrais retangulares ou quadradas em malhas previstas de desenho erudito regular que se baseava em princípios matemáticos e geométricos.

A higiene também constava no Código de Posturas que determinou "não se pode colocar esgotos, bueiros e lançar ou deixar na rua animaes mortos". Os animais deveriam ser retirados e enterrados fora dos limites da vila em local que os fiscais designassem. Em verdade, o Código de Posturas procurou modificar os hábitos cotidianos dos moradores. Era um "dos principais meios efetivamente viáveis para a Câmara controlar a transformação das práticas cotidianas". (Bortoloto, 2010, p.13). 0 artigo do Código de Posturas direcionado a saúde pública traz mecanismos disciplinadores da população na área urbana com o intuito de evitar a proliferação de doenças. As leis eram duras em se tratando de enfermidades contagiosas. Os que contraíam tais 
enfermidades sem assistência eram obrigados a deixar a cidade. 0 indivíduo que se encontrasse doente com moléstias contagiosas não poderia em nenhuma hipótese trabalhar em vendas de qualquer natureza sob pena de multa de $1 \$ 000$ réis. Quando o Intendente julgava necessário as vacinas eram solicitadas ao governo do Estado e depois de oito dias da inoculação das vacinas os moradores teriam que voltar para serem examinados pelo vacinador a fim de proceder verificação. Se houvesse epidemia, o Conselho designaria o local para onde deveriam ser levados os doentes. Em caso de morte por essas doenças teriam que ser sepultados com caixão fechado ficando proibido abrir a sepultura antes de dez anos. Como se vê trata-se de regras rígidas em caso de epidemias apesar de procurar tratá-los longe do município. A apresentação dessas medidas foi o resultado dos projetos que visavam a salubridade.

Curiosamente o parágrafo treze do art. 89 do Código de Posturas de 1907 traz uma advertência aos curandeiros frequentes da região. Nele advertia que "inculcar-se curandeiros de certas enfermidades por segredos, feitiços, ou orações ou tomar a cura por empreitada garantindo o seu êxito, se procederia uma pena de $20 \$ 000$ réis". Sabe-se que a este tempo parafraseando Sônia Maria Magalhães (2005) a medicina preventiva, apesar das intensas pesquisas e avanços científicos na identificação das doenças e a determinação de suas causas, caminhava vagarosamente, fato que contribuía para inúmeras especulações em torno do assunto. Mas, além disso, o curandeirismo era combatido por várias razões, dentre as quais, segundo Leicy Francisca da Silva (2005) [...]

[...] o século XX em Goiás marca o momento em que o corpo médico interessado em organizar-se como grupo e defender o monopólio sobre o seu espaço de trabalho inicia uma luta contra o que denominava charlatanismo [...] Um dos fatores que aqueciam os conflitos entre os grupos era a pequena distinção entre os resultados dos trabalhos médico-científico e médico-popular, frutos da falta de suporte técnico para o trabalho e também de uma formação profissional falha. A medicina não possuía ainda o aparato tecnológico que lhe permitisse alcançar grande número de resultados favoráveis gerando o descontentamento de uma população observada como objeto de uma ciência que lhes parecia afastada de sua realidade (Silva, 2005, p. 1-2).

Foi durante a República no Brasil que se incorporou o pensamento de progresso, de ordem, de urbanidade inaugurando um novo tempo, um novo ideal. Impulsionou a formação de espaços urbanos em que tudo se convergia para a ordem. "Uma cidade deve corresponder [...] a uma imagem de ordem". (Le Goff, 1998, p.111). Em Goiás, sob o domínio dos Bulhões surgiu uma resistência que durou grande parte da República Velha, marcadamente a partir de 1909, mas não impediu a influência da Igreja Católica nos assuntos políticos e administrativos estadual e/ou municipal. 0 Arraial Campo Formoso ao passar à categoria de Cidade desencadeou muitas disputas e controvérsias que marcaram a história da cidade no período republicano.

\section{A cidade Orizona sob a mira dos trilhos}

Desde o início do século XX que no Estado de Goiás há tendências de transformação com o seu processo de inserção no mercado nacional. Para tanto teve dois fatores fundamentais, o desenvolvimento da economia cafeeira no Centro-Sul do país e a penetração dos trilhos da estrada de ferro no Sudeste goiano. Foi no início do século XX que a reivindicação da ferrovia tomou forma liderada por Xavier de Almeida. Marcada pela construção da Estação Ferroviária de Araguari iniciou-se em 23/12/1909 com o ramal de Araguari a Goiandira, devendo atingir a Cidade de Goiás, na época capital do Estado. Três anos depois os trilhos chegavam ao sudeste do território goiano. Em 1913, a estrada de ferro chega à Ipameri, no ano seguinte a Roncador, em 1924 em Vianópolis e em 1935 a Leopoldo de Bulhões. A trajetória da E.F. Goyáz constituiu-se em duas fases sendo uma correspondente ao trecho Araguari-Roncador executada entre 1909 e 1914, período relativamente curto, considerando-se a difícil topografia da região. A segunda se deu após a construção da ponte de estrutura metálica, denominada Epitácio Pessoa, inaugurada em 1922 que propiciou estender os trilhos pela hinterlândia afora ligando e fundando povoados/ cidades, unindo espaços e gentes. A Estrada de Ferro de Goyáz tinha um papel dinamizador e sua missão era continuar em extensão até atingir a capital do Estado.

(c) Labor \& Engenho, Campinas [SP] Brasil, v.10, n.2, p.157-169, jan./mar. 2016. 
A cidade de Orizona não sofreu a influência do caminho férreo. Desde seu surgimento a cidade foi dotada de uma ordenação que assegurou seus traços fundamentais. Ali muitas histórias são contadas sobre as causas da "lonjura" com que passou a Estrada de Ferro Goyás. São narradas razões diversas, dentre elas, aquelas que dizem que o advento da "estrada traria muita coisa diferente, inclusive pessoas estranhas". Uns justificam que os políticos locais faziam articulações para impedir a entrada da estrada de ferro. Outros justificam que a estrada férrea não passou pela cidade por que custaria muito aos cofres públicos daí a razão dela ter mudado o seu rumo. A Estrada de Ferro cortou, em 1928, o município de Orizona pelos aglomerados de Ubatã e Egerinêo Texeira. Mais tarde foi construída uma estrada de terra feita à machados e foices como dizem localmente "a braço" pelo grupo empresarial do cel. Pio José da Silva com a intenção de ligar Campo Formoso a Estação Ferroviária recém fundada.

Em nossas visitas notamos que os orizonenses discorrem sobre suas raízes nutrindo pelo seu passado certa admiração. Olham para o seu passado com saudosismo e nostalgia. Um passado marcado pelas relações de poder com o sacralizado e com as elites. A cidade de Orizona em pouco mudou dos hábitos passados com suas casas de arquitetura colonial e seu meio econômico extremamente agropastoril. Por volta de 1950 a cidade de Orizona possuía edificados trezentos sessenta e dois prédios edificados em vinte e um logradouros sendo dezoito servidos de iluminação elétrica com trezentos e quarenta e duas ligações domiciliares. Cento e quarenta destes prédios eram abastecidos com agua canalizada. E assim permanecia em sua religiosidade de viés católico sobrevivendo em torno dos produtos vindos da terra e suas festas de cunho religioso. Uma cidade genuinamente conservadora em seus hábitos e costumes.

Já a força política de Orizona teve na figura do Senador José da Costa Pereira o ponto máximo da esfera do poder político local. Este senhor ficou conhecido na cidade como senador Zequinha Costa embora tenha sido prefeito da cidade por duas vezes. Viveu por toda sua vida na cidade em frente ao antigo fórum. Sua residência hoje se encontra abandonada, mas foi uma das construções considerada das mais "modernas" da época. Ela foi edificada aos moldes da arquitetura moderna com platibandas para esconder seus beirais, contudo o pé direito é baixo, o que nos levou a deduzir que do Art-Déco copiou-se, tão somente, os detalhes. Ressalta-se que as platibandas fizeram moda desde o início do século XX em Goiás. Esta casa de morada possuía, ainda, um sistema de aquecimento de água, no qual os canos de cobre passavam por dentro do fogão a lenha indo para os banheiros aquecendo água. A influência política desse ilustre orizonense ainda hoje desperta comentários dos mais velhos que o recordam caminhando pelas ruas da cidade todos os dias com sua bengala. Quanto a "lonjura" em que passou os trilhos atribuem a ele como o responsável pela estrada de ferro não passar dentro da cidade fazendo uma curva para desviar-se. Dizem que o mesmo temia a vinda de forasteiros que ofereceriam "perigos" a comunidade. Destarte fechou as portas da cidade aos trilhos. Mas a cidade de Orizona possuía suas entradas e saídas pelos quais se comunicou/comunica com a redondeza, com as suas vizinhas, enfim com o mundo exterior. Esse contato se fazia por terra e por água. Por meio da cavalgadura e, mais tarde, o avião e os automotores.

Vale dizer que a comunidade orizonense se nos apresentou indiferença ao se reportar a Estrada de Ferro Goyás. Demonstraram que para eles não houve expressividade e nada significou localmente o elemento representativo da "modernidade". 0 jeito confiante e naturalmente descritivo das razões da rejeição aos dormentes da Estrada de Ferro Goyás é cuidadosamente justificado remontando àquela maneira de vida urbana que apreende o fascínio e o horror das figuras estranhas, pois eram cientes que a complexidade da vida urbana moderna estava representada, também, pelos crimes. Assim sua comunidade formada por fazendeiros e gente do campo queriam o distanciamento do caminho férreo para evitar aquelas associações negativas dos indesejáveis, do barulho, da mundanidade, dentre outros.

\section{Considerações finais}

Sabemos que nenhum objeto de pesquisa se destaca por sua evidencia. 0 olhar do pesquisador e sua abordagem é que lhe delimitam os contornos. E "o conhecimento histórico progride não tanto para resolver os problemas quanto por modificar a forma de colocá-los". (Lepetit, 2011, p.59) Nosso objetivo aqui não foi a forma física da cidade, mas as mentalidades que ela suscita, pois como diz 
Lepetit (2011, p.39), "a cidade é, em si mesma, um objeto complexo em que se manifestam todos os fenômenos de interação, um conjunto que é mais do que a soma de suas partes". Para nós, a cidade Orizona representa o mito de si mesma e o fluxo humano proveniente do campo que a ela se dirigiu. A cidade tornou-se um instrumento primordial para antecipar, sugerir e condicionar mudanças sociais. A diferença desta cidade reside, fundamentalmente, na combinação da comodidade social, no vigor cultural e econômico que a distingue das demais. Não se pode ignorar o aspecto religioso presente no seu surgimento, em que a edificação da Capela fora o elemento condicionante. Numa palavra, a cidade de Orizona manteve suas tradições e seus modos de vida peculiares. Ela não se deixou dominar pelos ímpetos da apregoada modernidade. Em seu nascedouro foi influenciada pela Igreja Católica e pelos grandes latifúndios que trouxeram para na sua constituição os aspectos ruralistas. 0 edifício da antiga capela foi substituído pela Igreja Matriz que funciona como uma espécie de centro administrativo da cidade participando da vida social e política dos moradores. Compreender o que representou a fé católica para a construção do território e a recusa dos dormentes na história da cidade de Orizona [GO] traduz um aprendizado que nos ensina olhar, observar a diversidade, o emaranhado de suas formas e suas direções.

\section{Referências}

Boaventura, D. M. R. (2007). Urbanização em Goiás século VXIII. Tese de Doutorado, Universidade de São Paulo [FAUUSP], São Paulo, SP, Brasil.

Bourdieu, P. (1998). A escola cidadã no contexto da globalização. Petrópolis: Vozes.

Carvalho, H. F. (2004). As Posturas e o Espaço Urbano Comercial UFMA. Caderno Pós Ciências Sociais 1 (1), $31-42$.

Chartier, R. (1990). "Por uma sociologia histórica das práticas culturais". In A História Cultural. Rio de Janeiro: Bertrand Brasil.

Costa, E. V. da. (2010). Da Monarquia a República (9a ed.). São Paulo: Unesp.

Frémon. A. (1980). A região, espaço vivido. Coimbra: Livraria Almedina.

Gebara, A. (1986). O mercado de trabalho livre no Brasil (1871-1888). São Paulo: Brasiliense.

Guatari, F. (1985). Espaço e poder: a criação de territórios na cidade. Espaço \& Debates 5 (16).

Guimieiro, F. (2013). As ordens religiosas e a construção sócio-política na Brasil: Colônia e Império. Tuiuti: Ciência e Cultura, n. 46, 63-78.

Haesbaert, R. (1995). Desterritorialização: entre as redes e os aglomerados de exclusão. In E. I. de Castro et al. (Orgs.). Geografia: Conceitos e Temas. Rio de Janeiro: Bertrand Brasil.

Isnard, H. (1982). O espaço geográfico. Coimbra: Almedina.

Le Goff, J. (1998). Uma vida para a história: conversações com Marc Heurgon. São Paulo: Editora da Unesp.

Lepettit, B. (2001). Por uma nova Historia Urbana (H. A. Salgueiro, Org., C. Arena, Trad.). São Paulo: Edusp.

Micelli, S. (1988). A elite eclesiástica brasileira. Rio de Janeiro: Bertrand Brasil.

Mumford, L. (1961). A cultura das cidades (N. R. da Silva, Trad.). Belo Horizonte: Itatiaia.

Nascimento Filho, J. A. (2004). Senhores e escravos no Maranhão: ocupação e transgressão na São Luís oitocentista. Caderno Pós Ciências Sociais 1 (1), 31-42.

Ortoloto Carmo, B. (2010). Entre Práticas e Representações: Um estudo de caso do Código de Posturas de Santos (1857). Trabalho de Conclusão de Curso, Universidade Católica de Santos, Santos, SP, Brasil.

(c) Labor \& Engenho, Campinas [SP] Brasil, v.10, n.2, p.157-169, jan./mar. 2016. 
Santos, M. (1982). Espaço e sociedade. Petrópolis: Vozes.

Silva, H. R. da. (2000). A História como "a representação do passado": A nova abordagem da historiografia francesa. In: C. F. Cardoso, \& J. Malerba (Orgs.). Representações: Contribuição a um debate transdisciplinar. Campinas: Papirus.

Silva, L. F. (2005). A persistência de um saber: medicina popular em Goiás de 1930 a 1950. Anais do Simpósio Nacional de História, Londrina, PR, Brasil, 23. Disponível em: http://anpuh.org/anais/wpcontent/uploads/mp/pdf/ANPUH.S23.1327.pdf

Williams, R. (2011). O campo e a cidade na História e na Literatura. São Paulo: Companhia das Letras.

\subsection{Fontes primárias}

Código de Posturas de 1907, Prefeitura da cidade de Campo Formoso, Arquivo da cidade de Orizona [GO].

Lei Orgânica do Município de Campo Formoso, ano de 1907.

Código de Postura de 1906 da Cidade de Campo Formoso.

Ata do conselho de Intendência de 1906.

Ata do Conselho de Intendência de 1913.

Tabela de Impostos de 1909.

Livro do Tombo de 1912, Campo Formoso. Paróquia da cidade de Orizona, Goiás.

Livro do Tombo de 1918, Campo Formoso. Paróquia da cidade de Orizona.

Livro do Tombo de 1945, Paróquia Nossa Senhora da Piedade de Campo Formoso.

Lei Orçamentária de 1907.

Lei Orçamentária de 1917.

Lei no 13 de 17 de março de 1915.

Lei no 28 de 16 de maio de 1922.

Ofícios do Ministério da Agricultura, Indústrias e Comércio. Diretoria Geral de Estatística. № 7409, 3ํㅗ seção, 30 de setembro de 1915.

Ofício no 20092, 2aㅗ seção, 24 de novembro de 1938. Departamento dos Correios e Telégrafos.

Circular da Secretaria de Obras Públicas de Goiás, 22 de abril de 1918.

(C) Labor \& Engenho, Campinas [SP] Brasil, v.10, n.2, p.157-169, jan./mar. 2016. 